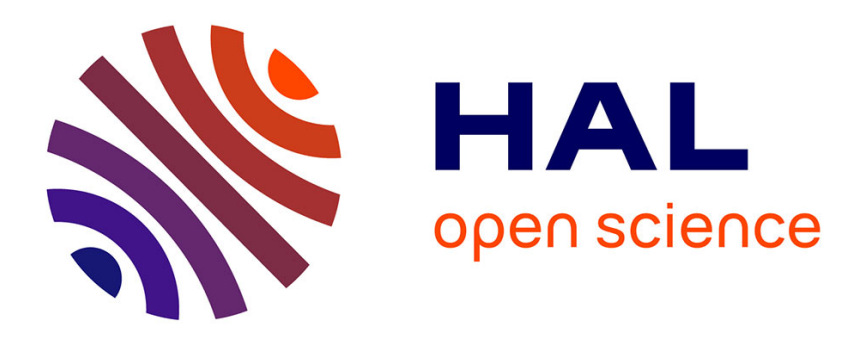

\title{
A consideration of adsorption processes in the CVD of polysilicon
}

\author{
M. Hitchman, J. Zhao
}

\section{To cite this version:}

M. Hitchman, J. Zhao. A consideration of adsorption processes in the CVD of polysilicon. Journal de Physique IV Proceedings, 1993, 03 (C3), pp.C3-115-C3-122. 10.1051/jp4:1993314 . jpa-00251371

\section{HAL Id: jpa-00251371 https://hal.science/jpa-00251371}

Submitted on 1 Jan 1993

HAL is a multi-disciplinary open access archive for the deposit and dissemination of scientific research documents, whether they are published or not. The documents may come from teaching and research institutions in France or abroad, or from public or private research centers.
L'archive ouverte pluridisciplinaire HAL, est destinée au dépôt et à la diffusion de documents scientifiques de niveau recherche, publiés ou non, émanant des établissements d'enseignement et de recherche français ou étrangers, des laboratoires publics ou privés. 


\title{
A consideration of adsorption processes in the CVD of polysilicon
}

\author{
M.L. HITCHMAN and J. ZHAO ${ }^{(1)}$ \\ Department of Pure and Applied Chemistry, University of Strathclyde, 295 Cathedral Street, Glasgow \\ G1 1XL, United Kingdon
}

\begin{abstract}
Although the growth mechanism of the CVD of polysilicon from silane has been extensively studied for some years, the chemistry of the gas-solid interactions is still not fully understood. In particular, there has been very little consideration of possible bonding modes of homogeneous silane species to silicon surfaces. In fact, most models of silicon growth from silane assume a simple, single site adsorption. In this paper we consider some models based on the interaction of $\mathrm{SiH}_{4}$ and $\mathrm{SiH}_{2}$ with dangling bonds on silicon surfaces. Initially, possible structures of silicon surfaces are described and then the adsorption and subsequent heterogeneous decomposition of silane species are examined. From this analysis it is concluded that it is rather unlikely that only a single site will be involved in any adsorption step, and that the most likely number of sites for adsorption of silicon containing species will be two. We then show that after the adsorption step, $\mathrm{SiH}_{2}$ probably plays an important role in forming $\mathrm{Si}$-Si bonds by rotational or translational steps with the loss of hydrogen. Finally, a more quantitative analysis is given to allow a comparison to be made between theory and experiment. The analysis confirms that the most likely route for interaction of gaseous species with the surface involves two adsorption sites and that subsequent surface dissociation of the adsorbed species leads to incorporation of silicon atoms into the crystal lattice.
\end{abstract}

\section{Introduction}

The CVD of polycrystalline silicon has been the subject of a large number of experimental and theoretical investigations for more than 20 years, and many publications have resulted; the topic has recently been reviewed [1]. Deposition of polysilicon from silane has been of special interest not only because of its technological importance, but also because it would appear to be a relatively simple chemical process: $\mathrm{SiH}_{4}(\mathrm{~g}) \rightarrow \mathrm{Si}(\mathrm{s})+2 \mathrm{H}_{2}(\mathrm{~g})$. However, the actual chemistry of the CVD of polysilicon from silane is somewhat more complex than this simple stoichiometric reaction would imply. In earlier theoretical modelling the reaction steps mainly considered were the adsorption of silane, the decomposition of adsorbed silane molecules on the surface and the incorporation of silicon into the lattice, and the desorption of adsorbed hydrogen to the gas phase [2-5]. More recently the initial homogeneous decomposition of $\mathrm{SiH}_{4}$ has also been explored extensively, and it is now generally agreed that thermal pyrolysis of silane via the elimination of $\mathrm{H}_{2}$ to form silylene $\left(\mathrm{SiH}_{4}(\mathrm{~g}) \rightarrow \mathrm{SiH}_{2}(\mathrm{~g})+\mathrm{H}_{2}(\mathrm{~g})\right.$ ) can also play a significant role in polysilicon CVD [6-8], especially at low pressures and high temperatures [9], with adsorption and surface decomposition of $\mathrm{SiH}_{2}$ followed by silicon incorporation and hydrogen desorption [10]. Most models based on both these approaches have been built around the assumption of single site adsorption. Little consideration has been given to possible bonding modes of homogeneous silicon containing species to a silicon surface. In this paper we begin to explore the interaction of $\mathrm{SiH}_{4}$ and $\mathrm{SiH}_{2}$ with dangling bonds on silicon surfaces. In order to do this we first of all consider the structure of silicon surfaces with different orientations. Then a kinetic model based on a consideration of dangling bond adsorption is developed for silicon deposition. Finally, some comparisons between theory and experiment are made.

\section{Consideration of silicon surface structure and dangling bonds}

There are three main types of silicon planes which need to be taken into account when considering surface processes. These are the (100), (110) and (111) planes. If we now consider an ideal silicon surface (i.e. 
with no crystalline defects), there are two free silicon orbitals per surface atom on a (100) plane, and one orbital per atom on each of the (110) and (111) planes. Figures 1-3 illustrate these surface dangling bond structures. Since any adsorption step in a LPCVD reaction will involve a surface chemical process, the adsorption of a tetrahedral silane molecule on these differently oriented surfaces would be expected to lead to different degrees of bonding. An example of the influence of substrate structure on adsorption properties can be observed for the adsorption of hydrogen on the silicon surfaces. Here there are differences for the activation energies of adsorption with a (100) surface showing $192 \mathrm{~kJ} \mathrm{~mol}^{-1}$, a (111) surface showing 176 $\mathrm{kJ} \mathrm{mol}^{-1}$ and a (110) surface showing $155 \mathrm{~kJ} \mathrm{~mol}^{-1}$ [11]. From this variation of the activation energy of hydrogen adsorbed on differently oriented silicon surfaces it could be expected that silane would also undergo different adsorption processes on the three types of surface, especially since the adsorption of silane on a silicon surface might well involve the hydrogen atoms in the silane molecule. Thus it is necessary to consider how dangling bonds could participate in adsorption before any kinetic model is developed.

A number of possibilities for silane adsorption on the three differently oriented surfaces can be considered. As we have already seen, for a silicon (100) plane, each atom on the top surface has two dangling bonds, but for silicon (110) and (111) planes there is only one dangling bond per atom. For any of the three differently oriented silicon surfaces, one, two, three or four of the peripheral hydrogen atoms in silane could be thought of as being in contact with the substrate to form $\mathrm{Si}-\mathrm{H}$ bonds. However, some simple considerations show that it is rather unlikely that one, three or four hydrogen atoms in a silane molecule will be adsorbed on a corresponding number of free sites, but rather that the most likely possibility is for silane to be adsorbed on these surfaces by interacting with two dangling bonds of two atoms. The reasons for this conclusion can be arrived at by considerations of the chemistry of silane dissociation, the structure of the silane molecule, the structure of the intermediate silylene, the structures of silicon top surfaces, and the movement of adsorbed species on the surfaces.

If first of all we consider a silane molecule in which the hydrogen atoms interact with a silicon surface, then if only one hydrogen is adsorbed on any type of surface this hydrogen will be left at the adsorption position and will liberate a silyl radical $\cdot \mathrm{SiH}_{3}$ to the gas phase. This surface process could be expressed as: $\mathrm{SiH}_{4}(\mathrm{~g})+\left[{ }^{*}\right] \rightarrow \cdot \mathrm{SiH}_{3}(\mathrm{~g})+\cdot \mathrm{H}^{*}$ (a). Here $*$ represents a free surface site, and $\cdot \mathrm{H}^{*}$ is a hydrogen atom which has been adsorbed on this site by forming a $\mathrm{Si}-\mathrm{H}$ adsorption bond. Now it is known from experimental and theoretical studies that silane decomposition reaction paths involving $\mathrm{H}$ and $\cdot \mathrm{SiH}_{3}$ radicals are energetically unfavourable $[6,12-15]$, especially when compared to the formation of silylene, $: \mathrm{SiH}_{2}$. For example, Ho et al [15] in a study of the heats of formation of $\mathrm{SiH}_{\mathbf{n}}$ compounds $(\mathrm{n}=1-4)$ found that the reaction enthalpy of $383.7 \mathrm{~kJ} \mathrm{~mol}^{-1}$ obtained for the reaction to form $\cdot \mathrm{SiH}_{3}$ and $\cdot \mathrm{H}$ was much higher than $250.6 \mathrm{~kJ} \mathrm{~mol}^{-1}$ for the reaction to form : $\mathrm{SiH}_{2}$ and $\mathrm{H}_{2}$. So, although from a steric point of view it would be possible for a silane molecule to adsorb on a single surface site through one hydrogen atom, the unfavourable reaction energetics would not favour this route. On the other hand, if we consider three or four hydrogen atoms of a silane molecule being involved in adsorption on a surface by interaction with three or four bonds of various surface sites, then a simple three dimensional model shows that because of the structure of a silane molecule this is sterically not very favorable and the simultaneous adsorption of this number of hydrogen atoms is unlikely [16]. Thus, the most probable scenario for the adsorption of silane on a silicon surface is by interaction with two free surface sites. This conclusion is supported by some recent SSIMS and TPD studies by Gates et al [17] of surface reactions in Si CVD from silane. On the basis of their results, they concluded that, at least on a (100) surface, the first step in the adsorption process is the adsorption of one silane molecule on two free surface sites, in agreement with our conclusion. It is interesting to note that Gates et al suggest that the product of this adsorption is a $\cdot \mathrm{H}^{*}$ and $\cdot \mathrm{SiH}_{3} *$. This, though, is not necessarily in contradiction with our argument above against the decomposition of $\mathrm{SiH}_{4}$ to form a silyl radical since that was for a gaseous $\mathrm{SiH}_{3}$ species; the energetics of formation of an adsorbed and a gaseous silyl radical are not likely to be the same. Studies of reactive sticking coefficients have also led Buss et al [18] to suggest silane interacting with two surface sites.

Having considered the adsorption of silane on a silicon surface we now briefly look at the possible adsorption of silicon containing radicals generated in the gas phase by thermal pyrolysis of silane. As indicated above and in the Introduction, the most likely product of homogeneous decomposition of sitane is the silylene biradical, $: \mathrm{SiH}_{2}$. Clearly, if this is formed then the most sterically favourable interaction with a silicon surface will be with two adjacent surface sites, and energetically it will be by formation of bonds with the unbonded electrons of the Si atom in the silylene radical rather than with the hydrogen atoms of the radical. 
So far the discussion of interaction of $\mathrm{SiH}_{4}$ and : $\mathrm{SiH}_{2}$ with silicon surfaces has been in general terms. However, in order to obtain a better understanding of the mechanism of a surface process we need to consider specific surfaces, and in this paper we take Si(111) as an example for discussing possible adsorption situations with silane or its dissociated species : $\mathrm{SiH}_{2}$. For the silicon (111) structure it can be seen from Fig. 3 that any two dangling bonds in the top layer of silicon atoms which have a common silicon atom in the second layer have the same distance between them, that all dangling bonds are vertical to the surface, and that one site gives one dangling bond. The silicon atoms labelled 1, 2,3 and 4 (see Fig.4) are taken for considering an adsorption process. When a silane molecule moves to a silicon (111) surface, any pair of dangling bonds supplied by, for example, silicon atoms 1 and 2 , or 1 and 4 , or 2 and 4 will be suitable for adsorbing two hydrogen atoms. Considering the case of silicon atoms 1 and 2 , after silane loses two hydrogen atoms to these two silicon atoms, silylene $\left(: \mathrm{SiH}_{2}\right)$ could either rotate to silicon atom 4 and form a Si(surface atom)-- $\mathrm{SiH}_{2}$ bond or it may transfer horizontally to the position of atoms 3 and 4 to form $\mathrm{Si}$ (surface atom)-Si( $\left.\mathrm{H}_{2}\right)$-Si(surface atom). From the point of kinetic energy, there is no difference between these two possibilities. A silylene radical is a non-linear triatomic molecule which will have three degrees of freedom for each of the modes of translation, rotation and vibration. Associated with each translational and rotational coordinate there is an energy of $1 / 2 \mathrm{kT}$ per molecule and so movement of a $: \mathrm{SiH}_{2}$ radical in the way described above could occur equally well by translation or rotation. However, the high energy ( $326.8 \mathrm{~kJ} \mathrm{~mol}^{-1}$ [19] ) associated with the formation of a Si-Si bond would probably favour concerted formation of two Si-Si bonds. This high bond energy would also encourage the adsorption of a silylene biradical from the gas phase, and again two surface sites would probably be involved (see Fig.5).

Adsorption of $\mathrm{SiH}_{4}$ and $: \mathrm{SiH}_{2}$ on the other two silicon surfaces (110) and (100) has been considered in detail elsewhere [16], and the same conclusion can be drawn that interaction with two surface sites is more likely than with a single site or with more than two sites. This is useful since it means that for polysilicon deposition we do not have to be unduly concerned about which particular crystal face growth is occurring on. From the qualitative analysis of surface adsorption the importance of the biradical $: \mathrm{SiH}_{2}$ either as a precursor to adsorption or as an intermediate in forming Si-Si bonds is also apparent in all cases. We now consider quantitative kinetic models based on these qualitative pictures of adsorption. Details of experimental conditions have been published previously [10] and are also given in ref. [16].

\section{Kinetic models based on surface reactions}

In the models which follow we assume low pressure conditions (i.e. no effect of diffusional transport), that the adsorption steps are in equilibrium, and that the rate limiting step is a heterogeneous decomposition. First of all we take a general model for the adsorption of $\mathrm{SiH}_{4}$ on 1,2 or 3 surface sites. This will allow us to examine the qualitative description given above and to see if the two site model is the most appropriate. Then we consider a model involving decomposition of adsorbed silylene.

(i). Decomposition by adsorbed silane

For the general case of silane adsorption on $\mathbf{x}$ surface sites we can write:

$$
\mathrm{SiH}_{4}(\mathrm{~g})+\mathrm{x}[*] \underset{\mathrm{k}_{\mathrm{dl}}}{\stackrel{\mathrm{k}_{\mathrm{al}}}{\Leftrightarrow}}\left[\mathrm{SiH}_{4} \mathrm{x} *\right] \quad \mathrm{K}_{\mathrm{s}}=\frac{\mathrm{k}_{\mathrm{a} 1}}{\mathrm{k}_{\mathrm{d} 1}}
$$

The adsorbed silane will then undergo $\mathrm{Si}-\mathrm{H}$ bond scission and move to adjacent sites to form a Si-Si bond. This series of steps can be represented by:

$$
\begin{aligned}
& \mathrm{Si}-\mathrm{H} \text { bond broken } \quad\left[\mathrm{SiH}_{4} \mathrm{x}^{*}\right] \quad \rightarrow \mathrm{SiH}_{4-\mathrm{x}}(\mathrm{g})+\mathrm{x}\left[\mathrm{H}^{*}\right] \\
& \text { Radical adsorption } \mathrm{SiH}_{4-\mathrm{x}}(\mathrm{g})+\mathrm{n}[*] \Leftrightarrow\left[\mathrm{SiH}_{4-\mathrm{x}} \mathrm{n}^{*}\right] \quad \mathrm{n}=1,2 \\
& \text { Decomposition } \quad\left[\mathrm{SiH}_{4-\mathrm{x}} \mathrm{n}^{*}\right] \quad \rightarrow\left[\mathrm{Si} \mathrm{n}^{*}\right]+\frac{4-\mathrm{x}}{2} \mathrm{H}_{2}(\mathrm{~g})
\end{aligned}
$$

The overall process can be expressed as:

$$
\left[\mathrm{SiH}_{4} \mathrm{x}^{*}\right]+\mathbf{n}[*] \stackrel{\mathrm{k}_{3}}{\rightarrow}\left[\mathrm{Si} \mathrm{n}^{*}\right]+\mathrm{x}\left[\mathrm{H}^{*}\right]+\frac{4-\mathrm{x}}{2} \mathrm{H}_{2}(\mathrm{~g})
$$


In addition we assume there is an equilibrium involving hydrogen which involves two free surface sites

$$
\mathrm{H}_{2}(\mathrm{~g})+2\left[{ }^{*}\right] \quad \stackrel{\mathrm{k}_{\mathrm{a}}}{\stackrel{\mathrm{k}_{d}}{a}} 2 \mathrm{H}^{*} \quad \mathrm{~K}_{\mathrm{H}}=\frac{\mathrm{k}_{\mathrm{a}}}{\mathrm{k}_{\mathrm{d}}}
$$

The rate of reaction $\left(R_{S}\right)$ for silicon formation based on reaction (R.2) is given by:

$$
R_{S}=k_{3}\left[\mathrm{SiH}_{4} \times *\right] \theta_{*}^{n}
$$

and from expressions which can be simply derived for the fractional coverage of silane and free surface sites, equation (E.1) becomes:

$$
R_{S}=\frac{k_{3}\left(K_{S} P_{S_{i} H_{4}}\right)^{\frac{1}{x}}}{\left[1+\left(K_{H} P_{H_{2}}\right)^{\frac{1}{2}}+\left(K_{S} P_{S i H_{4}}\right)^{\frac{1}{x}}\right]^{2 n}}
$$

This equation can be readily tested if the input silane concentration is very low and an inert carrier gas such as helium is used so that the hydrogen partial pressure is also very low. Then, assuming neither $K_{S}$ or $K_{H}$ is large (and there is in good evidence this is so [3]), equation (E.2) can be simplified to the following equations for the cases where $\mathrm{x}=1,2$ or 3 .

$$
\begin{array}{ll}
R_{S}=k_{3}\left(K_{S} P_{\mathrm{SiH}_{4}}\right)^{1} & x=1 \\
R_{S}=k_{3}\left(K_{S} P_{S_{i H}}\right)^{\frac{1}{2}} & x=2 \\
R_{S}=k_{3}\left(K_{S} P_{S_{H}}\right)^{\frac{1}{3}} & x=3
\end{array}
$$

According to these equations a plot of the rate of silicon deposition as a function of the partial pressure of silane raised to the appropriate power should be linear and pass through the origin. Using data taken from ref. [16] the plots shown in Fig.6 are obtained. It is seen that only equation (E.4) fits the experimental results with a straight line passing through the origin. Thus, the qualitative picture based on dangling bonds of silane adsorption requiring the occupation of two free surface sites is given some quantitative support.

(ii). Decomposition by adsorbed silylene

In the qualitative description given in Section 2 above, the importance of the silylene biradical $: \mathrm{SiH}_{2}$ either as a homogeneous intermediate or as an adsorbed intermediate has been mentioned. There is no doubt that : $\mathrm{SiH}_{2}$ plays an important role in the CVD of silicon, even though the exact nature of this role may still not be clear. We now extend our quantitative consideration of the adsorption process in polysilicon growth by specifically including : $\mathrm{SiH}_{2}$ in the mechanism. We do this in terms of adsorption and heterogeneous decomposition of $: \mathrm{SiH}_{2}$ produced in the gas phase, but it can be shown [16] that identical expressions are obtained if one takes the case of heterogeneous decomposition of silylene produced as a result of silane adsorption. On the basis of the earlier qualitative analysis and the quantitative analysis of the last section we now only consider two site adsorption.

The three step mechanism of gas phase dissociation to produce the silylene radical, the adsorption of this radical on two surface sites and its decomposition to form silicon can be represented by: 


$$
\begin{array}{lll}
\mathrm{SiH}_{4}(\mathrm{~g}) & \stackrel{\mathrm{k}_{1}}{\stackrel{\leftrightarrow}{\mathrm{k}_{-1}}} \mathrm{SiH}_{2}(\mathrm{~g})+\mathrm{H}_{2}(\mathrm{~g}) & \mathrm{K}_{1}=\frac{\mathrm{k}_{1}}{\mathrm{k}_{-1}} \\
\mathrm{SiH}_{2}(\mathrm{~g})+2[*] & \stackrel{\mathrm{k}_{\mathrm{a} 2}}{\stackrel{\mathrm{k}}{\mathrm{d} 2}}\left[\mathrm{SiH}_{2} 2 *\right] & \mathrm{K}_{\mathrm{S}^{\prime}}=\frac{\mathrm{k}_{\mathrm{a} 2}}{\mathrm{k}_{\mathrm{d} 2}} \\
{\left[\mathrm{SiH}_{2} 2 *\right]} & \stackrel{\mathrm{k}_{3}}{\rightarrow}\left[\mathrm{Si} 2^{*}\right](\mathrm{s})+\mathrm{H}_{2}(\mathrm{~g}) &
\end{array}
$$

Simple algebraic analysis gives the growth rate $\left(R_{s}\right)$ of silicon as:

$$
\mathrm{R}_{\mathrm{S}}=\frac{\mathrm{k}_{3^{\prime}}\left(\mathrm{K}_{\mathrm{S}^{\prime}} \mathrm{K}_{1} \frac{\mathrm{P}_{\mathrm{SiH}_{4}}}{\mathrm{P}_{\mathrm{H}_{2}}}\right)^{\frac{1}{2}}}{\left[1+\left(\mathrm{K}_{\mathrm{H}} \mathrm{P}_{\mathrm{H}_{2}}\right)^{\frac{1}{2}}+\left(\mathrm{K}_{\mathrm{S}^{\prime}} \mathrm{K}_{1} \frac{\left.\left.\mathrm{P}_{\mathrm{SiH}_{4}}\right)^{\frac{1}{2}}\right]}{\mathrm{P}_{\mathrm{H}_{2}}}\right]\right.}
$$

This equation is seen to be similar in form to equation (E.2), and when the approximations of low silane and low, but constant, hydrogen partial pressure are made then it reduces to an equation equivalent to equation (E.4). So again the two site model would be supported. The full equation can be tested, though, by taking values of the various thermodynamic and kinetic parameters. These can be calculated from data in the literature and from our own experimental results [16].

Two cases can be considered. One corresponding to polysilicon CVD from an input gas mixture of $\mathrm{SiH}_{4}$ and $\mathrm{H}_{2}$, and the other to an input mixture of $\mathrm{SiH}_{4}$ and $\mathrm{He}$. Here we only deal with the latter case; a more detailed analysis has been made in ref. [16]. A comparison between theoretical and experimental growth rates at $580^{\circ} \mathrm{C}$ is made for the $\mathrm{SiH}_{4} / \mathrm{He}$ system in Fig.7. Both equations (E.2) and (E.6) have been tested and it appears that the latter equation fits the data much better than the former, and this would underline the importance of silylene in the overall growth process.

(iii). Comparison with other published models

It is interesting to examine our model in the light of previously published models, all of which have assumed adsorption on a single surface site. Claassen and Bloem [20] and Hitchman et al [3] have, for example, all based their analyses on a simple rate determining decomposition of adsorbed silane. Van den Brekel and Bollen [4] took the decomposition of adsorbed silylene as rate limiting while Claassen et al [21] have considered the effect of adsorbed hydrogen on growth rate. Finally, Kuiper et al [22] have a model based on the decomposition of adsorbed silylene occupying one site with an inert carrier gas. The specific experimental conditions of, for example, deposition temperature and pressure reported in all these cases have been similar but not identical. Therefore, we have taken the models and fitted them to our experimental results. Figure 8 shows our experimental data and the calculated curves for the various models. Apart from the two site adsorption model given here, the model of ref. [22] comes closest to fitting the data points. The rest, however, deviate quite markedly from the experimental results. A closer and more detailed analysis would be needed to examine whether one can distinguish between our two site model and the single site model of Kuiper et al [22]. In situ experimental investigations would also help to differentiate between the various possibilities of surface adsorption.

\section{Conclusions}

On the basis of the exploratory analysis presented in this paper, there would seem to be some evidence for the involvement of two surface sites in the initial adsorption step for polysilicon deposition and of the importance of silylene in the growth mechanism. Further experimental and theoretical work is needed to examine the problem in greater depth. 


\section{Acknowledgements}

We are pleased to acknowledge financial support for JZ from Taiyuan University of Technology, PRC, the University of Strathclyde, Air Products plc and Epichem Ltd. Air Products and Epichem are also thanked for the provision of gases for the research.

\section{References}

[1] M.L. Hitchman and K. F. Jensen in " Chemical Vapor Deposition -- Principles and Applications" (ed. M. L. Hitchman and K. F. Jensen ), Academic Press, London, 1993, Ch.4

[2] M. J. P. Duchemin, M. M. Bonnet and M. F. Koelsch, J. Electrochem. Soc., 125 (1978) 637

[3] M. L. Hitchman, J. Kane and A. E. Widmer, Thin Solid Films, 59 (1979) 231

[4] C. H. J. Van Den Brekel and L. J. M. Bollen, J. Cryst. Growth, 54 (1981) 310

[5] R. Cadoret and F. Hottier, J. Cryst. Growth, 64 (1983) 583

[6] R. T. White, R. L. Espino-Rios, D. S. Rogers, M. A. Ring, and H. E. O'Neal, Int. J. Chem. Kinet., 17 (1985) 1029

[7] J. M. Jasinski, B. S. Meyerson and B. A. Scott, Ann. Rev. Phys. Chem., 38 (1987) 109

[8] H. K. Moffat, K. F. Jensen and R. W. Carr, J. Phys. Chem., 95 (1991) 145

[9] B. A. Scott, R. D. Estes and J. M. Jasinski, J. Chem. Phys., 89 (1988) 2544

[10] M. L. Hitchman, W. Ahmed, S. Shamlian and M. Trainor, Chemtronics, 2 (1987) 147

[11] K. D. Brzoska and Ch. Kleint, Thin Solid Films, 34 (1976) 131

[12] J. W. Erwin, M. A. Ring, and H. E. O'Neal, Int. J. Chem. Kinet., 17 (1985) 1067

[13] M. S. Gordon, D. R. Gano, J. S. Binkley, and M. J. Frisch, J. Am.Chem. Soc., 108 (1986) 2191

[14] S. K. Shin and J. L. Beauchamp, J. Phys. Chem., 90 (1986) 1507

[15] P. Ho, M. E. Coltrin, J. S. Binkley and C. F. Melius, J. Phys. Chem., 89 (1985) 4647

[16] J. F. Zhao, Ph.D. Thesis, University of Strathclyde, 1992, Ch.4, and results to be published

[17] S.M. Gates, C. M. Greenlief, S. K. Kulkarni and H. H. Sawin, J. Vac. Sci. Technol., A 8 (1990) 2965

[18] R. J. Buss, P. Ho, W. G. Breiland and M. E. Coltrin, J. Appl. Phys., 63 (1988) 2808

[19] D. R. Lide, "Handbook of Chemistry and Physics", 73rd Edn., (1992-1993) 9-129

[20] W. A. P. Claassen and J. Bloem, Philips J. Res., 36 (1981) 122

[21] W. A. P. Claassen, J. Bloem, W. G. J. N. Valkenburg and C. H. J. Van Den Brekel, J. Crystal Growth, 57 (1982) 259

[22] A. E. T. Kuiper, C. J. H. Van Den Brekel, J. de Groot and G. W. Veltkamp, J. Electrochem. Soc., 129 (1982) 2288

[23] J. Bloem, Acta Electronica, 21 (1978) 201
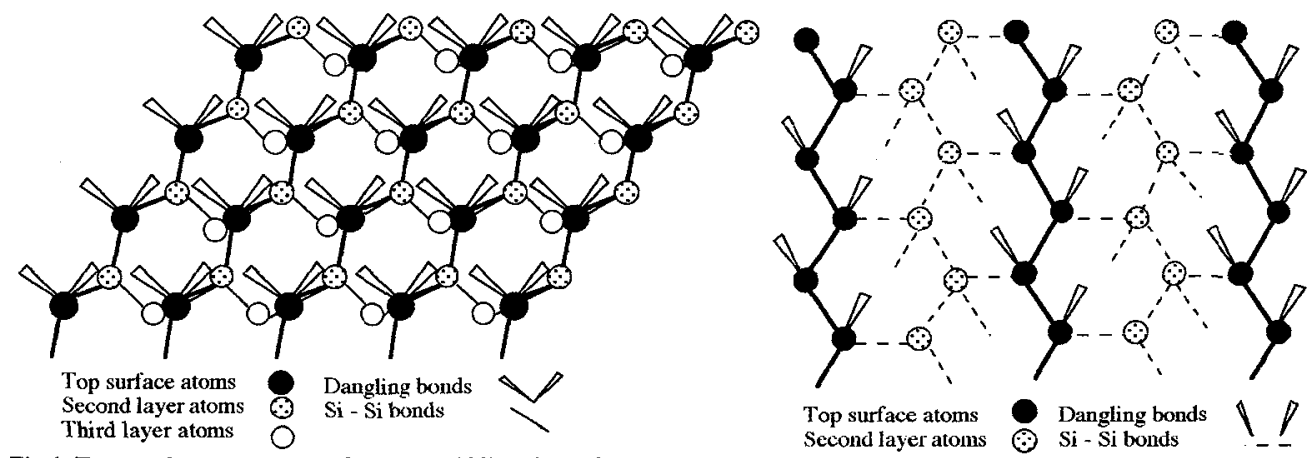

Fig.1 Top surface structure of silicon (100) orientation

Fig.2 Top surface structure of silicon (110) orientation 

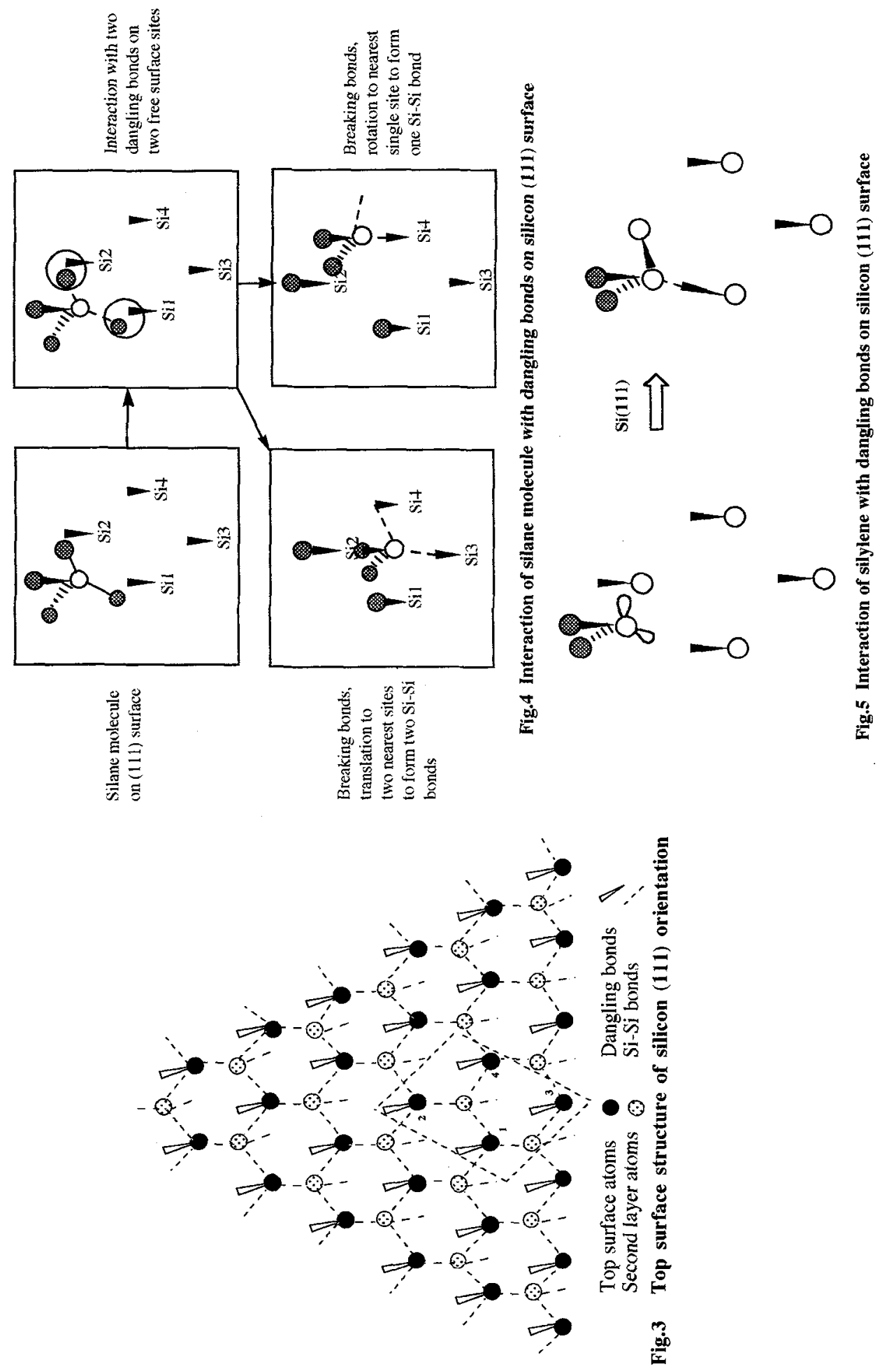


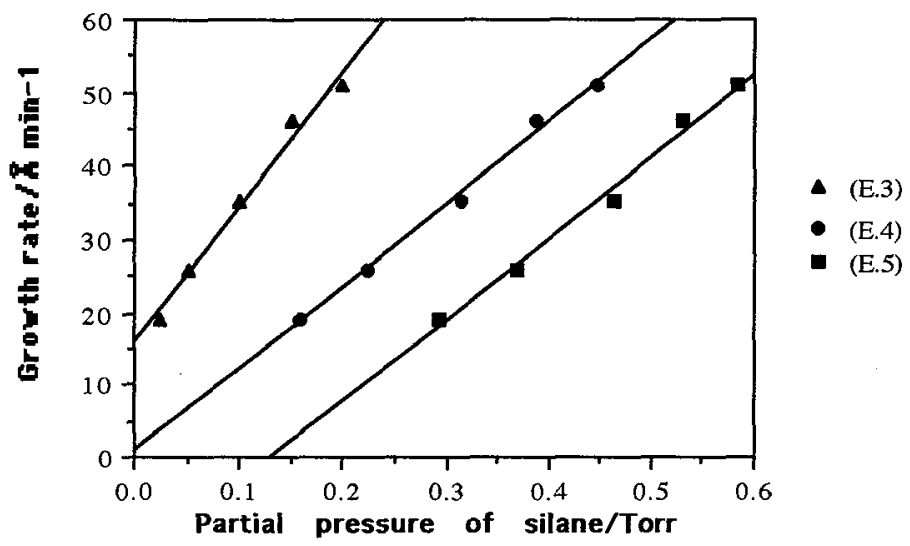

Fig.6 Test of equations (E.3) - (E.5) for the SiH4/He system

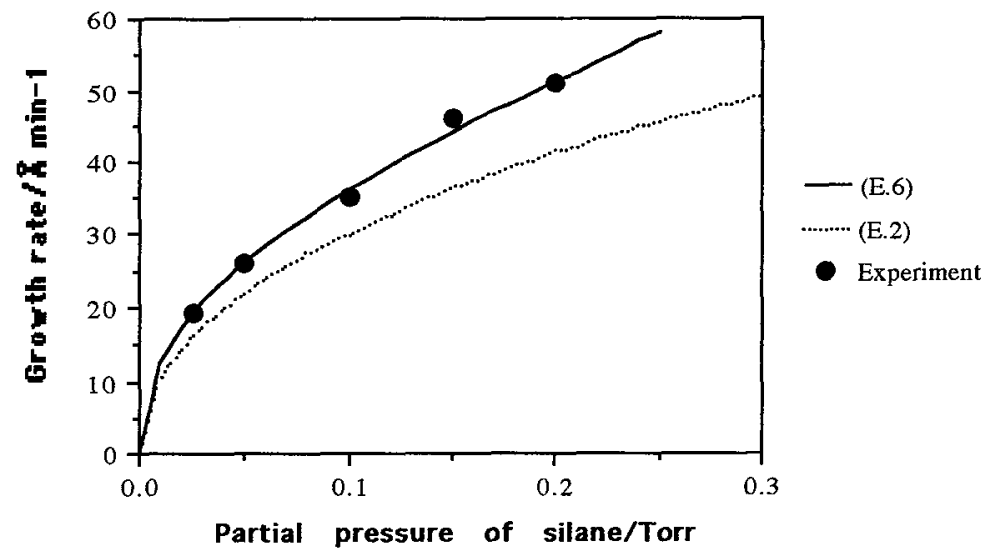

Fig.7 Test of equations (E.2) and (E.6) for the SiH4/He system

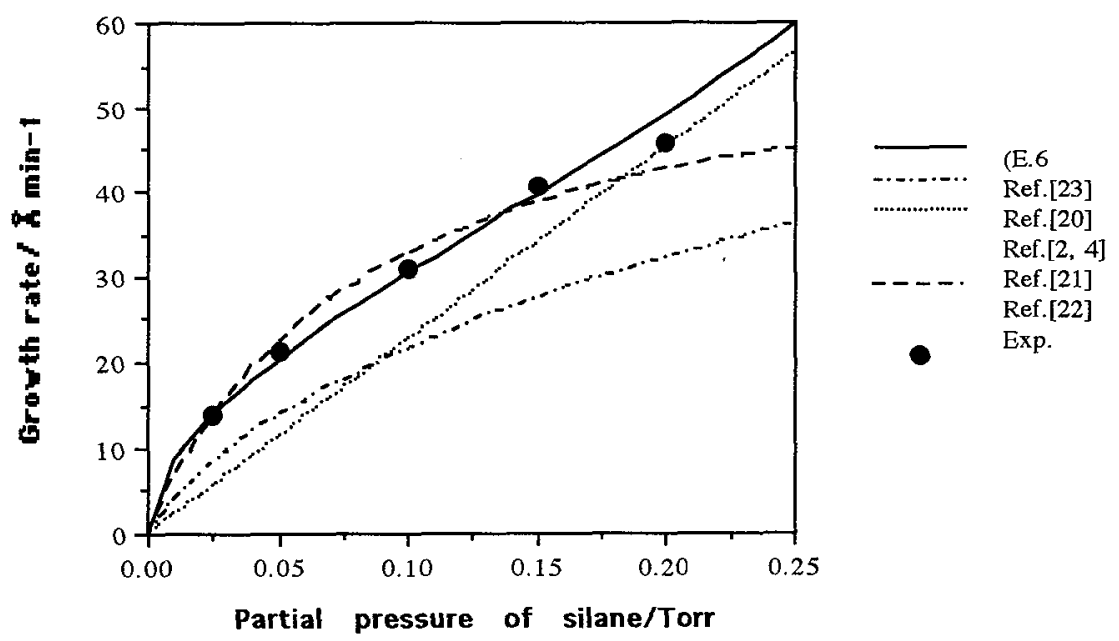

Fig.8 Comparison of experimental growth rates (this work) with various models 